\title{
EGFR-mediated expression of aquaporin-3 is involved in human skin fibroblast migration
}

\author{
Cong $\mathrm{CAO}^{\star} \S$, Yun SUN†, Sarah HEALEY*, Zhigang Blł, Gang HU§, Shu WAN*, Nicola KOUTTAB\|, Wenming CHU \\ and Yinsheng WAN*1 \\ *Department of Biology, Providence College, 549 River Ave., Providence, RI 02918, U.S.A., †Department of Obstetrics and Gynaecology, Renji Hospital of Shanghai Jiaotong University, \\ Shanghai, People's Republic of China, łDepartment of Dermatology, Jiangsu Provincial Hospital of Nanjing Medical University, Nanjing 210029, Jiangsu, People's Republic of China, \\ $\S$ Laboratory of Reproductive Medicine and Neuropharmacology, Nanjing Medical University, Nanjing 210029, Jiangsu, People's Republic of China, „|Department of Pathology, \\ Roger Williams Medical Center, Boston University, Providence, RI 02908, U.S.A., and $\uparrow$ Department of Molecular Microbiology and Immunology, Brown University, \\ Providence, RI 02903, U.S.A.
}

\begin{abstract}
AQP3 (aquaporin-3), known as an integral membrane channel in epidermal keratinocytes, facilitates water and glycerol movement into and out of the skin. Here, we demonstrate that AQP3 is also expressed in cultured human skin fibroblasts, which under normal wound healing processes migrate from surrounding tissues to close the wound. EGF (epidermal growth factor), which induced fibroblast migration, also induced AQP3 expression in a time- and dose-dependent manner. $\mathrm{CuSO}_{4}$ and $\mathrm{NiCl}_{2}$, previously known as AQP3 water transport inhibitors, as well as two other bivalent heavy metals $\mathrm{Mn}^{2+}$ and $\mathrm{Co}^{2+}$, inhibited EGF-induced cell migration in human skin fibroblasts. AQP3 knockdown by small interfering RNA inhibited EGF-induced AQP3 expression and cell migration. Furthermore, an EGFR (EGF receptor) kinase inhibitor, PD153035, blocked EGF-induced AQP3 expression and
\end{abstract}

cell migration. MEK [MAPK (mitogen-activated protein kinase)/ ERK (extracellular-signal-regulated kinase) kinase]/ERK inhibitor U0126 and PI3K (phosphoinositide 3-kinase) inhibitor LY294002 also inhibited EGF-induced AQP3 expression and cell migration. Collectively, our findings show for the first time that AQP3 is expressed in human skin fibroblasts and that EGF induces AQP3 expression via EGFR, PI3K and ERK signal transduction pathways. We have provided evidence for a novel role of AQP3 in human skin fibroblast cell migration, which occurs during normal wound healing.

Key words: aquaporin-3 (AQP3), cell migration, epidermal growth factor receptor (EGFR), human skin fibroblast, phosphoinositide 3-kinase (PI3K), wound healing.

\section{INTRODUCTION}

AQPs (aquaporins) are a family of small ( $\sim 30 \mathrm{kDa} /$ monomer), hydrophobic, integral membrane proteins that are expressed widely in animal and plant kingdoms, with 13 members having been identified in mammals so far [1,2]. AQPs are expressed in various epithelia and endothelia involved in fluid transport, as well as in cell types that are originally thought not to carry out fluid transport, such as AQP3 expression in the basal layer of keratinocytes in mammalian skin [2,3], although the functions of AQP3 in human skin keratinocytes remains to be further elucidated.

AQP3, initially cloned from a rat kidney [4], is a member of a family of homologous AQP water channels expressed ubiquitously in mammalian epithelia and endothelia that facilitate fluid transport. Phenotypic studies in AQPs knockout mice have implicated the involvement of AQPs in the urinary concentrating mechanism in kidney, water movement in lung, cerebral water balance, exocrine gland secretion and mechano-electrical signal transduction [2,5]. In the skin, AQP3 was first found in the basal layer of epidermal keratinocytes. Mice deficient in AQP3 have dry skin with reduced stratum corneum hydration, decreased elasticity and impaired biosynthesis [6]. Mechanistic analysis of the altered skin phenotype in AQP3-deficient mice suggests that the glycerol and water transportation function of AQP3 are important in normal skin physiology $[3,6,7]$.
Another important characteristic of AQP3-null mice is the delayed recovery of skin wound healing compared with that of wild-type mice $[7,8]$. Yet, the cellular mechanism of this phenomenon remains to be elucidated. Wound healing is a dynamic, well-organized and complex process that requires the orchestration of cellular processes of different cell types [9]. Re-epithelialization, connective tissue deposition and contraction are initiated temporally to facilitate wound closure. Dermal fibroblasts actively and dynamically contribute to wound healing by migrating to the wound site, synthesizing extracellular matrix components such as collagen, forming granulation tissue [10], and generating mechanical forces within the wound to initiate wound contraction [11].

Dermal fibroblast cell migration is considered a fundamental step towards wound healing. Cell migration involves the transient formation of membrane protrusions (lamellipodia and membrane ruffles) at the leading edge of the cell. This process is thought to require rapid local changes in ion fluxes and cell volume, which are probably accompanied by rapid transmembrane water movement [12,13]. Investigation of a possible role of AQP1 in tumour angiogenesis has revealed an unanticipated function of AQP1 and AQP4 in cell migration [14]. Recent studies have further shown that AQP1 in the region of membrane protrusions enhances water entry and thus facilitates the dynamics of cell membrane protrusions and cell motility/migration $[2,14-16]$.

Abbreviations used: AQP, aquaporin; DMEM, Dulbecco's modified Eagle's medium; EGF, epidermal growth factor; EGFR, EGF receptor; ERK, extracellular-signal-regulated kinase; FBS, fetal bovine serum; HRP, horseradish peroxidase; JNKi, c-Jun-N-terminal kinase inhibitor; MAPK, mitogen-activated protein kinase; MEF, mouse embryonic fibroblast; MEK, MAPK/ERK kinase; PI3K, phosphoinositide 3-kinase; RNAi, RNA interference; siRNA, small interfering RNA.

1 To whom correspondence should be addressed (email yswan@providence.edu). 
While molecular mechanism of cell migration remains complicated [17], numerous studies have shown that EGF (epidermal growth factor), which activates EGFR (EGF receptor), leads to increased cell migration [18-22]. Therefore this supports the role of EGF and EGFR in normal development and pathophysiological events such as tumour cell invasion, metastasis, cell migration and wound healing. Studies using exogenous application of EGF, by enhancing human skin fibroblasts cell migration, also have reported an enhancement of epithelialization during wound repair $[23,24]$.

Given that human skin keratinocytes express AQP3 and that EGF plays an important role in cell migration, we undertook the present study to investigate whether the water channel AQP3 is expressed in human skin fibroblasts and whether EGF induces human fibroblast cell migration. If so, the question remains whether AQP3 mediates EGF-induced human skin fibroblast cell migration. Using Western blotting, immunofluorescence, phagokinetic track motility assay and in vitro wound healing assay, we observed that AQP3 is expressed in human skin fibroblasts in addition to human keratinocytes. EGF, via EGFR, PI3K (phosphoinositide 3-kinase) and ERK (extracellular-signal-regulated kinase) signal transduction pathways, induces AQP3 expression, which is involved in cell migration in cultured human skin fibroblasts.

\section{MATERIALS AND METHODS}

\section{Cell culture}

Human skin fibroblasts (CRL-2522; A.T.C.C., Manassas, VA, U.S.A.) and spontaneously immortalized human keratinocytes (HaCat cell line) were maintained in DMEM (Dulbecco's modified Eagle's medium) (Sigma, St. Louis, MO, U.S.A.) supplemented with $10 \%(\mathrm{v} / \mathrm{v}$; for human skin fibroblasts) or $6 \%$ (for HaCat cells) FBS (fetal bovine serum), penicillin/streptomycin (1:100; Sigma) and $4 \mathrm{mM}$ L-glutamine, in a $\mathrm{CO}_{2}$ incubator at $37^{\circ} \mathrm{C}$. For Western blotting, cells were reseeded in six-well plates at a density of $0.2 \times 10^{6}$ cells $/ \mathrm{ml}$ with fresh complete culture medium. Morphological changes were observed under a phasecontrast microscope.

\section{Antibodies and reagents}

Rabbit anti-AQP3 was obtained from Chemicon (Temecula, CA, U.S.A.) and rabbit anti-phospho-EGFR $\left(\mathrm{Tyr}^{1068}\right)$ was obtained from Cell Signaling Technology (Beverly, MA, U.S.A.). Rabbit anti-EGFR (1005), goat anti-rabbit IgG-HRP (horseradish peroxidase) and goat anti-mouse IgG-HRP antibody were received from Santa Cruz Biotechnology (Santa Cruz, CA, U.S.A.). Monoclonal mouse anti- $\beta$-actin was obtained from Sigma. PD153035, U0126 and LY294002 were from Calbiochem (San Diego, CA, U.S.A.). $\mathrm{CuSO}_{4}, \mathrm{NiCl}_{2}, \mathrm{MnSO}_{4}, \mathrm{CoSO}_{4}, \mathrm{ZnCl}_{2}$ and $\mathrm{MgCl}_{2}$ were from Sigma.

\section{Phagokinetic track motility assay}

As described previously [25], 12-well plates were coated with coating medium of $20 \mu \mathrm{g} / \mathrm{ml}$ fibronectin (Sigma) in PBS, and placed in a $\mathrm{CO}_{2}$ incubator at $37^{\circ} \mathrm{C}$ for at least $2 \mathrm{~h}$. After removing the coating medium gently with a Pasteur pipette, the wells were washed with PBS and $2.4 \mathrm{ml}$ of microsphere suspension $(86 \mu \mathrm{l}$ of stock microbeads solution in $30 \mathrm{ml}$ of PBS) was added to each well. The plates were then centrifuged at $500 \mathrm{~g}$ at $4{ }^{\circ} \mathrm{C}$ for $20 \mathrm{~min}$ and carefully transferred to a $\mathrm{CO}_{2}$ incubator and incubated at $37^{\circ} \mathrm{C}$ for at least $1 \mathrm{~h}$. Supernatant $(1.8 \mathrm{ml})$ was removed from each well, and finally 1500 freshly trypsinized cells in $2 \mathrm{ml}$ of assay medium (DMEM supplemented with $0.05 \%$ FBS) were seeded per well. Cells with or without treatment were cultured for $24 \mathrm{~h}$ and photographed in a microscope.

\section{In vitro wound healing ('scratch') assay}

As described in [26], 12-well plates were precoated with polylysine $(30 \mu \mathrm{g} / \mathrm{ml})$, followed by further BSA blocking. A sufficient number of serum-starved HaCaT cells or human skin fibroblasts were plated so that they became confluent in the wells right after attachment $(\sim 1-2 \mathrm{~h})$. Same area of each well is then displaced by scratching a line through the layer with a pipette tip. Floating cells were removed by washing with PBS. Media containing $0.2 \%$ FBS without or with indicated concentrations of EGF were added to the wells and incubated for an additional $24 \mathrm{~h}$. Mitomycin C $(10 \mu \mathrm{g} / \mathrm{ml})$ was always included in the media to prevent cell proliferation. Five representative images of the scratched areas under each condition were photographed. To estimate the relative migration of the cells, the unclosed cell-free areas from five prints under each condition were excised. 'Average gap' (average gap, percentage) was used to quantify the data. The polylysine alone at $0 \mathrm{~h}$ was considered $100 \%$ of average gap.

\section{Western-blot analysis}

As reported previously [27,28], cultured human skin fibroblasts or keratinocytes with or without treatment were washed with cold PBS and harvested by scraping into $150 \mu \mathrm{l}$ of RIPA buffer (containing $50 \mathrm{mM}$ Tris/HCl, pH 7.4, $150 \mathrm{mM} \mathrm{NaCl}, 1 \%$ Nonidet P40, $1 \mathrm{mM}$ EDTA and $0.25 \%$ sodium deoxycholate) with $1 \mathrm{mM}$ $\mathrm{NaF}, 10 \mu \mathrm{M} \mathrm{Na}_{3} \mathrm{VO}_{4}, 1 \mathrm{mM}$ PMSF and protease inhibitor cocktail (10 $\mu \mathrm{g} / \mathrm{ml}$ leupeptin, $10 \mu \mathrm{g} / \mathrm{ml}$ aprotinin and $1 \mu \mathrm{M}$ pepstatin). Cell lysates were incubated in $4^{\circ} \mathrm{C}$ for $30 \mathrm{~min}$. After centrifugation at $10000 \mathrm{~g}$ for $10 \mathrm{~min}$ at $4^{\circ} \mathrm{C}$, protein concentration was determined by a Bio-Rad protein assay (Bio-Rad, Hercules, CA, U.S.A.). Then, $20 \mu \mathrm{g}$ of proteins (for AQP3, phosphoEGFR and EGFR) or $10 \mu \mathrm{g}$ of proteins (for $\beta$-actin) were denatured in $5 \times \mathrm{SDS} / \mathrm{PAGE}$ sample buffer for $5 \mathrm{~min}$ at $95^{\circ} \mathrm{C}$. The proteins were separated by SDS/10\% PAGE or SDS/7.5\% PAGE and transferred on to PVDF membrane (Millipore, Bedford, MA, U.S.A.) for $2 \mathrm{~h}$ at $4{ }^{\circ} \mathrm{C}$. Non-specific binding was blocked with $10 \%$ dry milk in TBST (20 mM Tris/HCl, $137 \mathrm{mM}$ $\mathrm{NaCl}$ and $0.01 \%$ Tween 20, $\mathrm{pH} 7.4$ ) for $1 \mathrm{~h}$ at room temperature $\left(22^{\circ} \mathrm{C}\right)$. After blocking, membranes were incubated with specific antibodies against AQP3 (1:1000), EGFR (1:1000), phosphoEGFR $(1: 1000)$ and $\beta$-actin $(1: 20000)$ in dilution buffer $[2 \%$ $(\mathrm{w} / \mathrm{v}) \mathrm{BSA}$ in TBS] overnight at $4{ }^{\circ} \mathrm{C}$. The blots were incubated with HRP-conjugated anti-rabbit or anti-mouse $\mathrm{IgG}$ at appropriate dilutions and room temperature for $1 \mathrm{~h}$. Antibody binding was detected using the $\mathrm{ECL}^{\circledR}$ (enhanced chemiluminescence) detection system following the manufacturer's instructions and visualized by autoradiography with Hyperfilm.

\section{RNAi (RNA interference) experiments}

Custom SMART pool ${ }^{\circledR}$ RNAi duplexes (more than four sequences) for AQP3 were chemically synthesized by Dharmacon Research (Lafayette, CO, U.S.A.). As described previously $[28,29]$, human skin fibroblasts were cultured in complete medium that did not contain antibiotics for 4 days. Cells $\left(50 \times 10^{4}\right)$ were seeded into a six-well plate 1 day prior to transfection and cultured to $60-70 \%$ confluence on the following day. For RNAi experiments, $12 \mu \mathrm{l}$ of FuGENE6 ${ }^{\mathrm{TM}}$ (Roche Diagnostics, Indianapolis, IN, U.S.A.) was diluted in $88 \mu \mathrm{l}$ of DMEM for $5 \mathrm{~min}$ in room temperature. Then, $10 \mu \mathrm{l}$ of $20 \mu \mathrm{M}$ double-stranded RNAs for AQP3 RNAi was mixed with DMEM containing FuGENE6 $^{\mathrm{TM}}$ and incubated for $30 \mathrm{~min}$ at room temperature for 


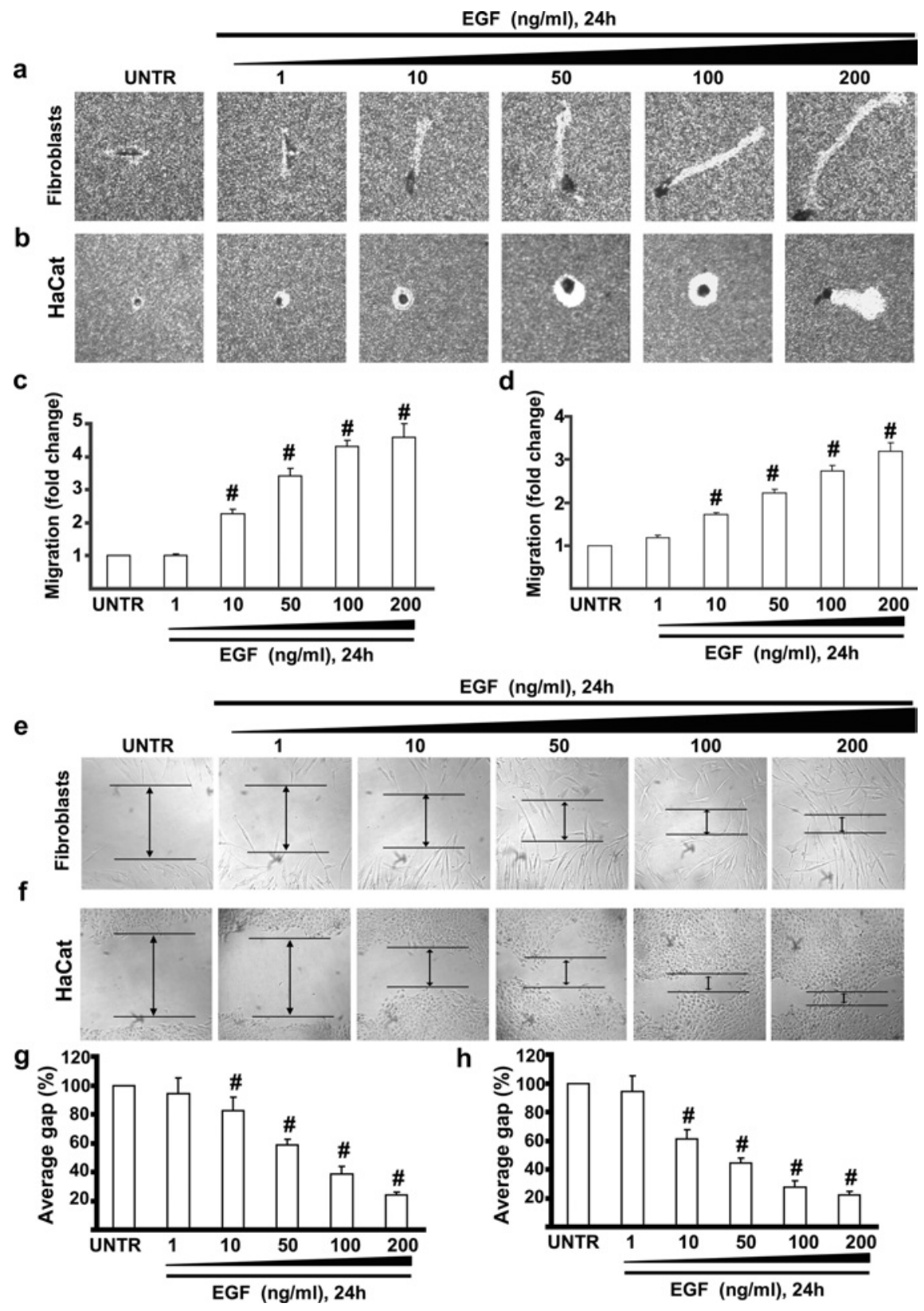

Figure 1 EGF induces cell migration and wound healing in human skin fibroblasts and keratinocytes

Human skin fibroblasts and kerationcytes (HaCat cells) were treated with EGF at the concentrations of 1, 10, 50, 100 and $200 \mathrm{ng} / \mathrm{ml}$, and cell migration was detected by phagokinetic track motility assay as described in the Materials and methods section, and photographed at $24 \mathrm{~h}$. EGF-induced human skin fibroblast and HaCat cell migrations are shown in (a) and (b) respectively. Human skin fibroblast and HaCat cell migrations were also expressed as fold change in (c) and (d) respectively. HaCaT cells and human skin fibroblasts were serum-starved overnight and subjected to in vitro wound-healing assays in the absence or presence of different doses of EGF. EGF-induced human skin fibroblast and HaCat cell in vitro wound healings are shown in (e) and (f) respectively which were expressed as average gap in $\mathbf{( g )}$ and $(\mathbf{h})$ respectively. The results represent means \pm S.E.M. for triplicate experiments. For cell migration experiment at least 50 cells' migration distance was counted for one experiment. $\# P<0.05$ versus untreated groups (lane 1). Magnification: $(\mathbf{a}, \mathbf{b}, \mathbf{e}, \mathbf{f}) 1: 100$. Abbreviation: UNTR, untreated.

complex formation. Finally, the complex was added to the well containing $2 \mathrm{ml}$ of medium with a final AQP3 siRNA (small interfering RNA) concentration of $100 \mathrm{nM}$. AQP3 protein expression and cell migration were determined by Western blotting and phagokinetic track motility assay respectively $48 \mathrm{~h}$ after treatment.

\section{Immunofluorescence}

As previously described [27,28], cultured human skin fibroblasts after treatment were fixed in cold acetone for $10 \mathrm{~min}$ at $4{ }^{\circ} \mathrm{C}$. Fixed cells were blocked with $10 \%(\mathrm{v} / \mathrm{v})$ goat serum in
TBST for $5 \mathrm{~min}$ at room temperature and then incubated with 1:200 rabbit anti-AQP3 (Chemicon) for $1 \mathrm{~h}$, followed by FITCanti-rabbit secondary antibody (Chemicon) at 1:100 for $30 \mathrm{~min}$ and AQP3 immunofluorescence was observed in a Zeiss fluorescence microscope and digitized.

\section{Statistical analysis}

The values in the Figures are expressed as the means \pm S.E.M. In the experiments involving cell migration and AQP3 expression, the values were representative of three different experiments. 
Statistical analysis of the data between the control and treated groups was performed by a Student's $t$ test. Values of $P<0.05$ were considered as statistically significant.

\section{RESULTS}

\section{EGF induces cell migration and in vitro wound healing in human skin fibroblasts and keratinocytes}

During normal skin wound healing, fibroblasts are recruited from the surrounding tissue and migrate into the granulation tissue and proliferate to close the wound [10]. Studies using exogenous application of EGF have reported an enhancement of epithelialization during wound repair [23,24]. We first tested whether EGF induces cell migration in human skin fibroblasts and keratinocytes, both of which are known to be involved in wound healing. Human skin fibroblasts and keratinocytes were cultured in 12-well plates coated with $20 \mu \mathrm{g} / \mathrm{ml}$ fibronectin as described in the Materials and methods section and treated with EGF at concentrations of 1, 10, 50, 100 and $200 \mathrm{ng} / \mathrm{ml}$. Cell migration was monitored and digitized $24 \mathrm{~h}$ after EGF treatment. The results showed that EGF induced cell migration in a dosedependent manner in human skin fibroblasts and keratinocytes (Figures 1a and 1b). Cell migration was increased by 1.1-, 2.3-, 3.5-, 4.3- and 4.5-fold in human skin fibroblasts (Figure 1c) and 1.2-, 1.7-, 2.2-, 2.8- and 3.2-fold in keratinocytes (Figure 1d) respectively after treatment with various concentrations of EGF when compared with untreated cells. These results clearly demonstrate that EGF strongly induces human skin fibroblast and keratinocyte migration. The results of the in vitro wound healing, which measures the averaged and directional migration of a cell population, confirmed these findings (Figures 1e and 1f). Human skin fibroblasts and keratinocytes were cultured in 12-well plates coated with polylysine $(30 \mu \mathrm{g} / \mathrm{ml})$ as described in the Materials and methods section and treated with EGF at concentrations of 1, $10,50,100$ and $200 \mathrm{ng} / \mathrm{ml}$. The results showed that EGF promoted in vitro wound healing in a dose-dependent manner in human skin fibroblasts (Figure 1e) and keratinocytes (Figure 1f). In vitro wound healing was quantified as average gap (percentage) in Figure 1(g) (for human skin fibroblasts) and Figure 1(h) (for HaCaT cells).

\section{EGF induces AQP3 expression in human skin fibroblasts and keratinocytes}

The study above demonstrated that EGF induced cell migration in both human skin fibroblasts and keratinocytes. Recent studies indicated that AQP3 null mice display delayed recovery of skin wound healing compared with wild-type mice [3,7,8]. AQPs enhance cell migration by facilitating water entry in the region of membrane protrusions $[2,14,15]$. We next investigated whether AQP3 is expressed in human skin fibroblasts and keratinocytes and whether EGF induces AQP3 expression. Cells were treated with EGF at concentrations of 1, 10, 50 and $100 \mathrm{ng} / \mathrm{ml}$ and cell lysates were then analysed for AQP3 by Western blotting as described in the Materials and methods section. As shown in Figure 2, AQP3 was expressed in human skin fibroblasts and keratinocytes and EGF induced AQP3 expression in a dose-dependent manner. EGF-induced AQP3 expression was increased by 1.2-, 1.6-, 2.3- and 3.1-fold in human skin fibroblasts (Figure 2a) and 1.1-, 1.7-, 2.0- and 3.8-fold in keratinocytes (Figure 2c), EGF also induced AQP3 expression in a time-dependent manner and AQP3 expression was increased remarkably at $12 \mathrm{~h}$ and reached 3.2- and 3.9-fold at $24 \mathrm{~h}$ in fibroblasts and keratinocytes respectively (Figures $2 \mathrm{~b}$ and $2 \mathrm{~d}$ ). Immuno- a

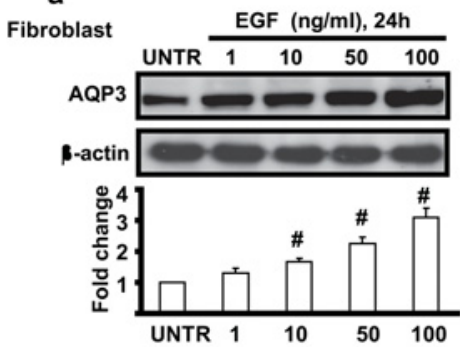

c

$\mathrm{HaCaT}$

aT b

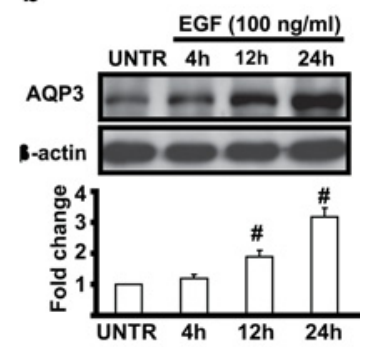

d

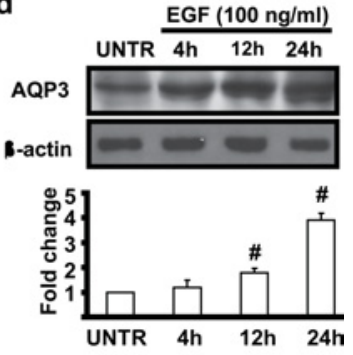

$\operatorname{EGF}(100 \mathrm{ng} / \mathrm{ml})$

e
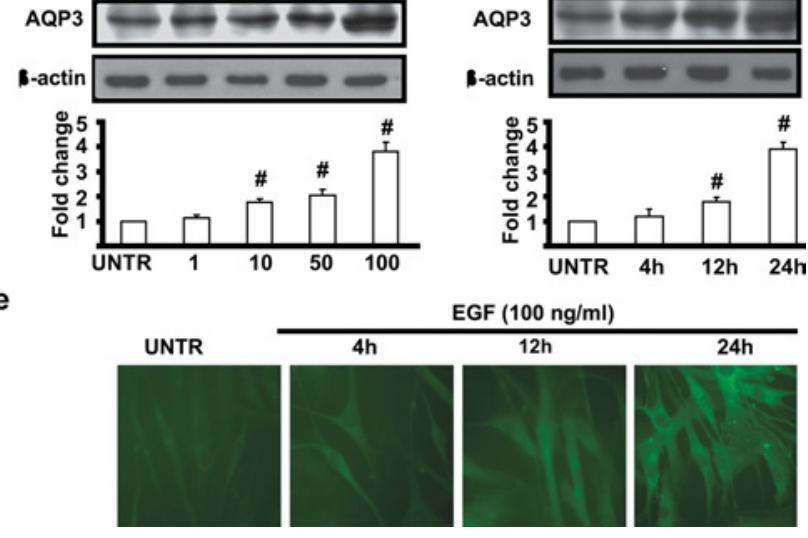

Figure 2 EGF induces AQP3 expression in human skin fibroblasts and keratinocytes

Human skin fibroblasts and keratinocytes (HaCat cells) were treated with various doses of EGF $(1,10,50$ and $100 \mathrm{ng} / \mathrm{ml})$ and harvested at $24 \mathrm{~h}$ as shown in (a) and (c) respectively, or treated with EGF (100 ng/ml) and harvested at different time points (4, 12 and $24 \mathrm{~h})$ as shown in (b) and (d). AQP3 expression in cell lysates was analysed by Western blotting and quantified as normalized to $\beta$-actin. Human skin fibroblasts were also treated with $100 \mathrm{ng} / \mathrm{ml}$ EGF and AQP3 expression was detected by the immunofluorescence method described above at different time points $(4,12$ and $24 \mathrm{~h})$ after EGF treatment as shown in $(\mathbf{e})$. The data represent mean \pm S.E.M. for triplicate experiments. \#P $<0.05$ versus untreated groups (lane 1). Magnification: (e) 1:400.

fluorescence microscopic results shown in Figure 2(e) further confirmed that EGF induced AQP3 expression in human skin fibroblasts.

$\mathrm{NiCl}_{2}, \mathrm{CuSO}_{4}, \mathrm{MnSO}_{4}$ and $\mathrm{CoSO}_{4}$ inhibit EGF-induced cell migration in human skin fibroblasts, but do not affect expression of AQP3

The data above clearly demonstrated that EGF induced AQP3 expression and cell migration in human skin fibroblasts and keratinocytes. To further study whether AQP3 is involved in EGFinduced cell migration, water and glycerol transport inhibitors of $\mathrm{AQP} 3, \mathrm{CuSO}_{4}$ and $\mathrm{NiCl}_{2}[30,31]$, were applied in the experiments. Human skin fibroblasts were treated with various concentrations of $\mathrm{CuSO}_{4}$ and $\mathrm{NiCl}_{2}$, together with $100 \mathrm{ng} / \mathrm{ml}$ of EGF for $24 \mathrm{~h}$. Cell migration was measured by phagokinetic track motility assay as described above. The results showed that both $\mathrm{CuSO}_{4}$ (Figure 3a) at a dose of $10-500 \mu \mathrm{M}$ and $\mathrm{NiCl}_{2}$ (Figure $3 \mathrm{~b}$ ) at dose of $100-1000 \mu \mathrm{M}$ significantly inhibited cell migration induced by EGF in human skin fibroblasts. While the inhibitory role of $\mathrm{CuSO}_{4}$ was detectable at a dose of $10 \mu \mathrm{M}$ and was most obvious at $500 \mu \mathrm{M}$ (Figure 3c), the effect of $\mathrm{NiCl}_{2}$ was detectable at a dose of $100 \mu \mathrm{M}$, and was most obvious at $1000 \mu \mathrm{M}$ (Figure 3d).

Published results have shown that water and glycerol transport of AQP3 is affected by mercury, which is also a bivalent heavy metal with the mechanism different from $\mathrm{NiCl}_{2}$ and $\mathrm{CuSO}_{4}$ [30-32]. We next examined whether other bivalent heavy metals 


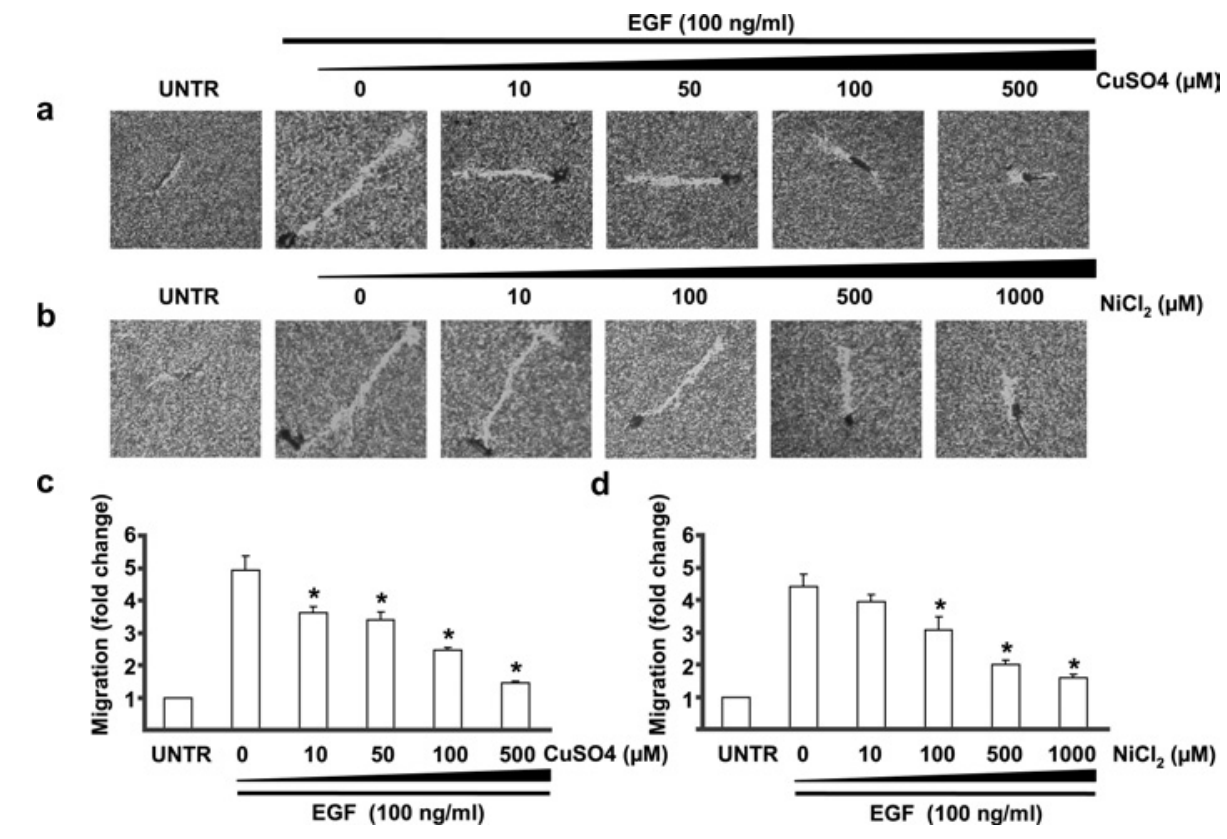

Figure $3 \mathrm{CuSO}_{4}$ and $\mathrm{NiCl}_{2}$ inhibit EGF-induced cell migration in human skin fibroblasts

Cells were treated with EGF (100 ng/ml) and $\mathrm{CuSO}_{4}(10,50,100$ and $500 \mu \mathrm{M})$ or $\mathrm{NiCl}_{2}(10,100,500$ and $1000 \mu \mathrm{M})$ as shown in (a) and (b) respectively. Cell migration was detected by phagokinetic track motility assay as described in the Materials and methods section and photographed at $24 \mathrm{~h}$ and cell migration was expressed as fold change for $\mathrm{CuSO}_{4}(\mathbf{c})$ and $\mathrm{NiCl}_{2}(\mathbf{d})$. The results represent the means \pm S.E.M. for triplicate experiments. For each experiment at least 50 cells' migration distance was counted. ${ }^{*} P<0.05$ versus EGF-treated groups (lane 2). Magnification: (a, b) 1:100.
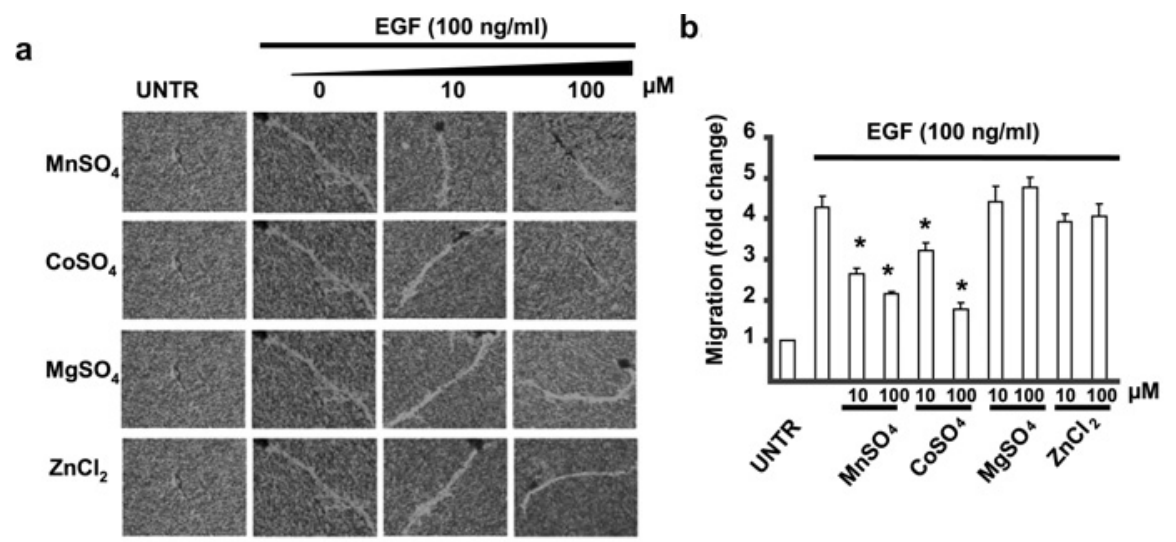

C
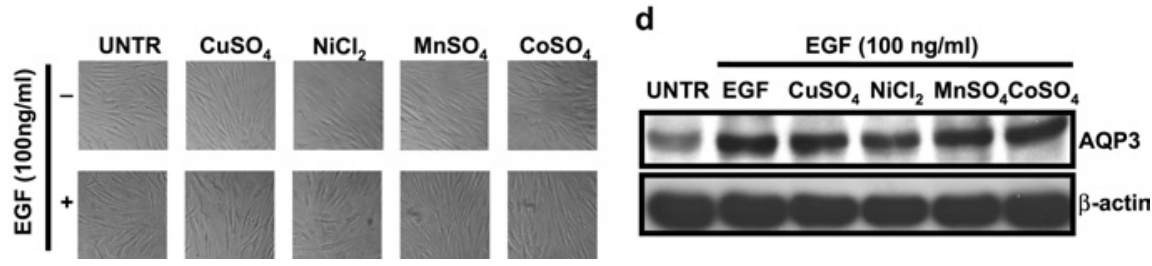

Figure $4 \mathrm{MnSO}_{4}$ and $\mathrm{CoSO}_{4}$ but not $\mathrm{MgSO}_{4}$ or $\mathrm{ZnCl}_{2}$, inhibit EGF-induced cell migration without affecting AQP3 expression or cell morphology in human skin fibroblasts

Cells were treated with EGF (100 ng/ml) together with 10 or $100 \mu \mathrm{M} \mathrm{MnSO}_{4}, \mathrm{CoSO}_{4}, \mathrm{MgSO}_{4}$ and $\mathrm{ZnCl}_{2}$. Cell migration was detected by phagokinetic track motility assay as described in the Materials and methods section and photographed at $24 \mathrm{~h}$ as shown in (a). Cell migration was expressed as fold change (b). Human skin fibroblasts were treated with $\mathrm{EGF}$ (100 ng/ml) together with or without $500 \mu \mathrm{M} \mathrm{CuSO}_{4}, 1000 \mu \mathrm{M} \mathrm{NiCl}_{2}, 100 \mu \mathrm{M} \mathrm{MnSO}_{4}$ or $100 \mu \mathrm{M} \mathrm{CoSO}_{4}$ for $24 \mathrm{~h}$, cell morphological change were observed under phase-contrast microscopy (c) and AQP3 expression in cell lysates was analysed by Western blotting (d). The results represent the means \pm S.E.M. for triplicate experiments. For cell migration experiment, at least 50 cells' migration distance was counted for one experiment. ${ }^{*} P<0.05$ versus EGF-treated groups (lane 2). Magnification: (a) 1:100.

such as $\mathrm{MnSO}_{4}, \mathrm{CoSO}_{4}, \mathrm{MgSO}_{4}$ and $\mathrm{ZnCl}_{2}$ have any effects on EGF-induced cell migration. We found that $\mathrm{MnSO}_{4}$ and $\mathrm{CoSO}_{4}$, but neither $\mathrm{MgSO}_{4}$ nor $\mathrm{ZnCl}_{2}$, at $10-100 \mu \mathrm{M}$ inhibited EGFinduced cell migration (Figures $4 \mathrm{a}$ and $4 \mathrm{~b}$ ). Both the morphology measured by a phase-contrast microscope (Figure 4c) and cell viability measured by MTT [3-(4,5-dimethylthiazol-2yl)-2,5-diphenyl-2H-tetrazolium bromide] (results not shown) were unchanged compared with untreated cells. Interestingly, 


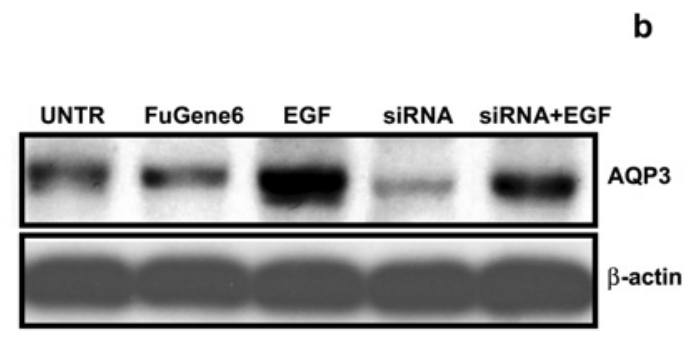

C
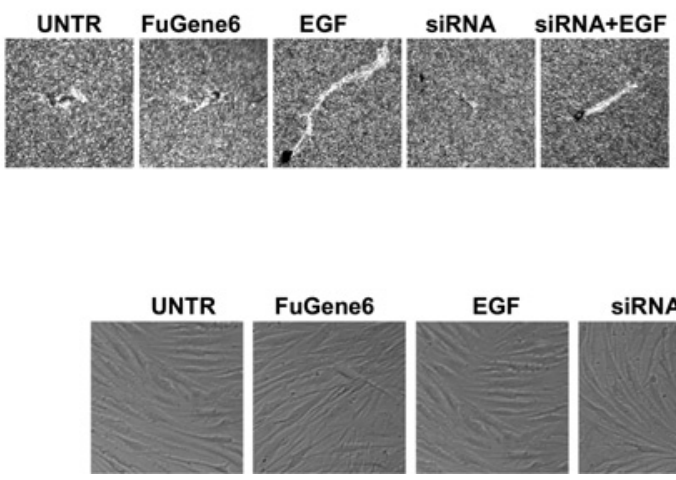

EGF

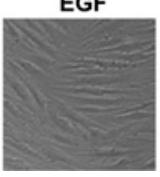

SIRNA

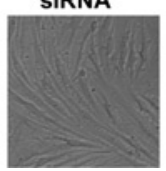

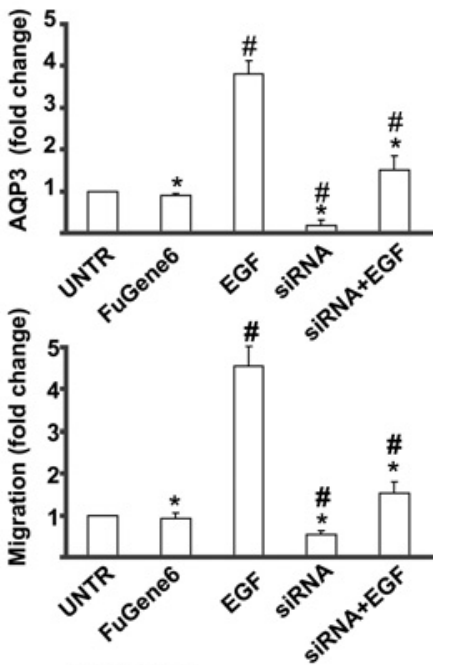

SIRNA+EGF

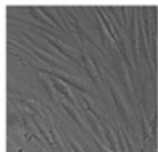

Figure 5 AQP3 knockdown reduces EGF-induced AQP3 expression and cell migration in human skin fibroblasts

Cells were treated with EGF (100 ng/ml) and $100 \mathrm{nmol}$ of AQP3 RNAi duplexes (more than four sequences) described above for $24 \mathrm{~h}$. AQP3 expression in cell lysates was analysed by Western blotting (a). Cell migration was detected by phagokinetic track motility assay as described in the Materials and methods section and photographed at $24 \mathrm{~h}$ (c). AQP3 expression and cell migration were expressed as fold change shown in (b) and (d) respectively. Cell morphological change was observed under phase-contrast microscopy (e). The results represent means \pm S.E.M. for triplicate experiments. For cell migration experiment, at least 50 cells' migration distance was counted for one experiment. \#P<0.05 versus untreated groups. ${ }^{\star} P<0.05$ versus EGF-treated groups. Magnification: (c) 1:100.

EGF-induced AQP3 expression was also not affected by $500 \mu \mathrm{M}$ $\mathrm{CuSO}_{4}, 1000 \mu \mathrm{M} \mathrm{NiCl}, 100 \mu \mathrm{M} \mathrm{MnSO}_{4}$ and $100 \mu \mathrm{M} \mathrm{ZnCl}$ (Figure 4d), which have been shown to inhibit EGF-induced cell migration.

\section{AQP3 knockdown inhibits EGF-induced AQP3 expression and cell migration in human skin fibroblasts}

To further examine the role of AQP3 in EGF-induced cell migration, RNAi experiments were performed. Human skin fibroblasts were cultured in complete medium that did not contain antibiotics for 4 days. Cells $\left(50 \times 10^{4}\right)$ were seeded into a six-well plate 1 day prior to transfection and cultured to $60-70 \%$ confluence on the following day. RNAi duplexes for AQP3 were mixed with FuGENE6 ${ }^{\mathrm{TM}}$ to form a transfection complex, which was added to cells in six-well plates. AQP3 protein expression and cell migration were determined by Western blotting and phagokinetic track motility assay after $48 \mathrm{~h}$. The results showed that RNAi duplexes treatment did not affect cell morphology (Figure 5e), but inhibited AQP3 protein expression by $65 \%$ (Figures $5 \mathrm{a}$ and $5 \mathrm{~b}$ ). As shown in Figures 5(c) and 5(d), AQP3 knockdown significantly inhibited EGF-induced cell migration to approx. $60 \%$.

\section{EGFR mediates EGF-induced AQP3 expression and cell migration in human skin fibroblasts}

To further understand the role of EGFR in EGF-induced AQP3 expression and cell migration, we used an EGFR kinase inhibitor, PD153035. Immunofluorescence microscopic data showed that pretreatment with PD153035 $(10 \mu \mathrm{M})$ blocked EGF (100 ng/ml)induced AQP3 expression, while PD153035 alone had no effect on AQP3 expression compared with untreated cells (Figure 6a). Western-blot results shown in Figures 6(b) and 6(c) further confirmed that EGFR kinase inhibitor blocked EGF-induced AQP3 expression. Moreover, cell migration induced by EGF also was inhibited by PD153035 (Figures 6d and 6e). As expected, EGF induced EGFR phosphorylation in a time-dependent manner and EGFR phosphorylation reached a peak at 5 min post-EGF treatment and remained elevated for $1 \mathrm{~h}$ (Figures $6 \mathrm{f}$ and $6 \mathrm{~g}$ ). These results indicate that activation of EGFR is important in EGF-induced AQP3 expression and cell migration in human skin fibroblasts. To further investigate whether EGFR is required for EGF-induced cell migration, we used EGFR knockout MEF (mouse embryonic fibroblast). The results showed that EGF induced cell migration in $\mathrm{EGFR}^{+/+} \mathrm{MEF}$ cells but not in $\mathrm{EGFR}^{-/-}$MEF cells (Figures 6h and 6i). However, using Westernblot methods, we failed to observe AQP3 expression in MEF cells.

\section{PI3K and ERK reinvolved in EGF-induced AQP3 expression and cell migration in human skin fibroblasts}

Abundant studies have shown that activation of EGFR results in phosphorylation and activation of various effector proteins [33], among which are MAPK (mitogen-activated protein kinase) [34] and PI3K [35-38]. The data above indicated that activation of EGFR is required for EGF-induced AQP3 expression and cell migration. Additional experiments were performed to further study the cell signalling pathways leading to EGF-induced AQP3 expression and cell migration, using pharmacological inhibitors. Western-blot analysis showed that pretreatment of PI3K inhibitor LY294002 $(10 \mu \mathrm{M})$ or MEK (MAPK/ERK kinase)/ERK inhibitor U0126 (100 nM) partially inhibited EGF (100 ng/ml)induced AQP3 expression (Figure 7a) and AQP3 expressions were decreased from 3.5-fold (EGF-treated) to 1.8-fold (LY294002treated) and 2.2-fold (U0126-treated) compared with untreated 
a

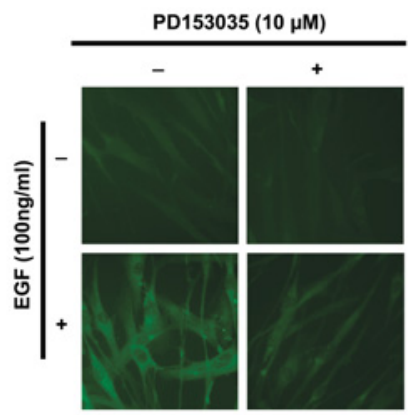

d

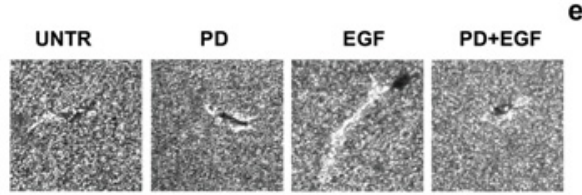

f

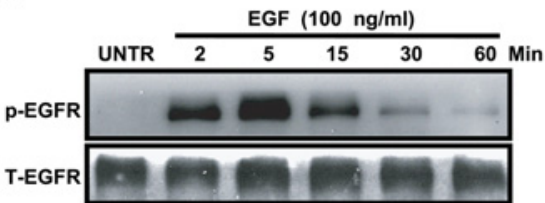

h

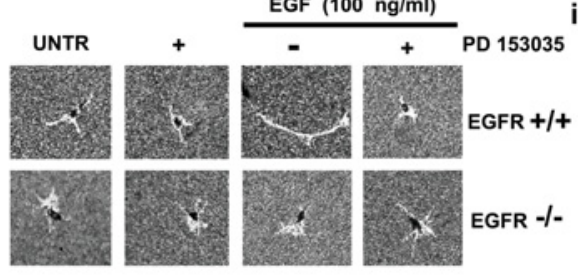

g

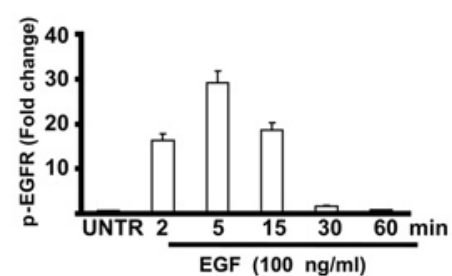

b

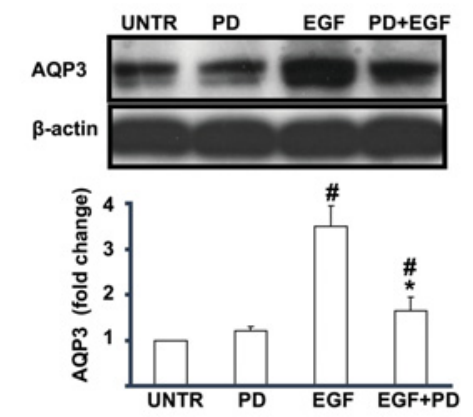

e

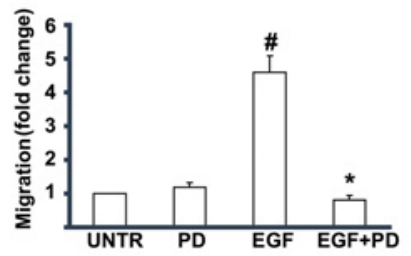

i

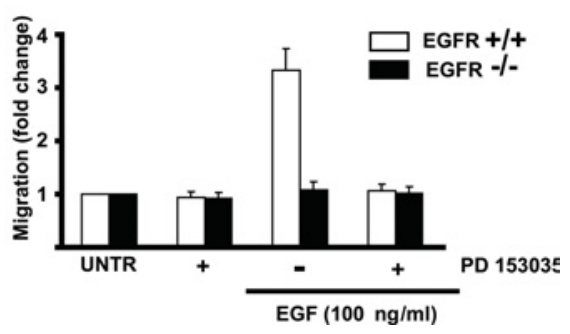

Figure 6 EGF-induced AQP3 expression and cell migration are blocked by PD153035

Cells were treated with EGF (100 ng/ml) with or without EGFR kinase inhibitor PD153035 (100 nM) for $24 \mathrm{~h}$. Immunofluorescence method described above was used to detect AQP3 expression (a). AQP3 expression in cell lysates was also analysed by Western blotting as shown in (b). Cell migration was detected by phagokinetic track motility assay as described in the Materials and methods section and photographed in (d). AQP3 expression and cell migration were expressed as fold change shown in (c) and (e) respectively. For EGFR phosphorylation, cells were treated with EGF $(100 \mathrm{ng} / \mathrm{ml})$ and harvested at different time points $(2,5,15,30$ and $60 \mathrm{~min})$, phospho-EGFR (p-EGFR) and total EGFR (T-EGFR) in cell lysates were analysed by Western blotting (f) and was quantified in $(\mathbf{g})$. Wild-type and EGFR knockout MEF cells were treated with mouse EGF (100 ng/ml) with or without EGFR kinase inhibitor PD153035 (100 nM) for $24 \mathrm{~h}$ and cell migration was detected by phagokinetic track motility assay as described in the Materials and methods section and photographed in (h) and quantified in (i). The results represent the means \pm S.E.M. for triplicate experiments. For cell migration experiment, at least 50 cells' migration distance was counted for one experiment. $\# P<0.05$ versus untreated groups. ${ }^{\star} P<0.05$ versus EGF-treated groups. Magnification: (a) 1:400 and (d, h) 1:100.

cells. As shown in Figures 7(c) and 7(d), EGF-induced cell migration (4.8-fold compared with untreated cell) was inhibited by LY294002 (2.0-fold) and U0126 (2.2-fold). Neither JNKi (c-Jun$\mathrm{N}$-terminal kinase inhibitor) nor p38 inhibitor (SB203580) had any effect on EGF-induced AQP3 expression and cell migration (result not shown). These data indicate that PI3K and ERK pathways are involved in EGF-induced AQP3 expression and cell migration in human skin fibroblasts.

\section{DISCUSSION}

The healing of human skin wounds is a dynamic, well-organized and complex process requiring co-ordination of cellular activities of many different cell types [9]. Dermal fibroblasts among others are actively involved in this process, migrating to the wound site, proliferating, synthesizing extracellular matrix components, forming granulation tissue [10], and generating mechanical forces within the wound to initiate wound contraction [11,39-41]. Numerous studies have shown that EGF activates its receptor, consequently leading to increased cell migration in human skin fibroblasts [18-22], thereby supporting the notion that EGF, through its receptor, plays an important role in cell migration and wound healing. Our study, using phagokinetic track motility assay and in vitro wound healing experiment, clearly demonstrated that EGF induced both human skin fibroblasts and keratinocytes cell migration (Figures 1a-1d), which have been reported to be involved in wound healing (Figures 1e-1h). 
a
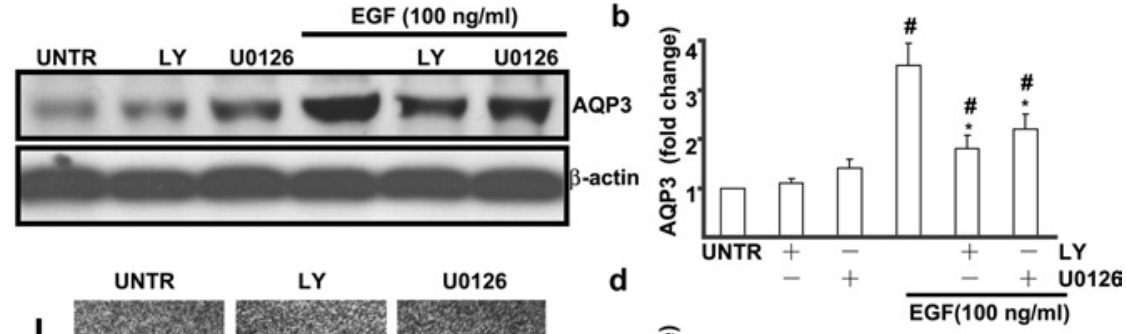

C
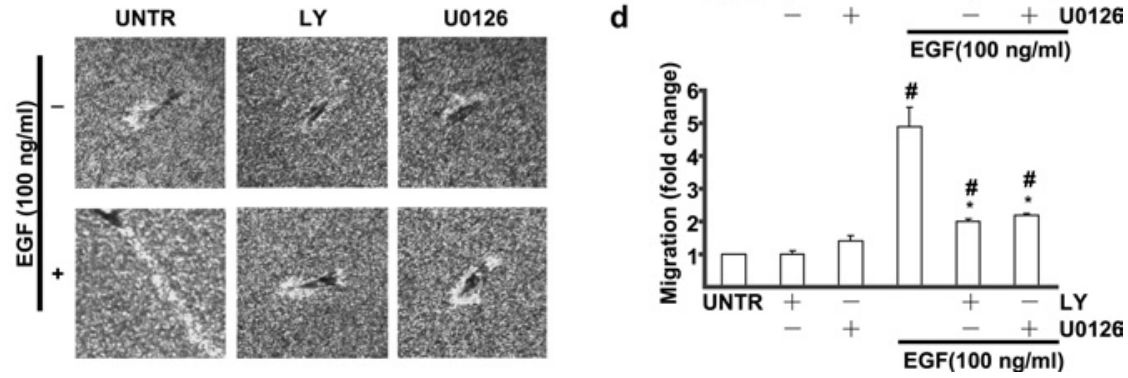

Figure 7 LY294002 and U0126 inhibit EGF-induced AQP3 expression and cell migration in human skin fibroblasts

Cells were treated with EGF (100 ng/ml) and PI3K inhibitor LY294002 (10 $\mu \mathrm{M})$, or MEK/ERK inhibitor U0126 (100 nM) for $24 \mathrm{~h}$. AQP3 expression was detected by Western blotting (a). Cell migration was detected by phagokinetic track motility assay as described in the Materials and methods section and photographed at $24 \mathrm{~h}$ (c). AQP3 expression and cell migration were expressed as fold change shown in (b) and (d) respectively. The results represent the means \pm S.E.M. for triplicate experiments. For migration experiment, at least 50 cells' migration distance was counted for one experiment. $\# P<0.05$ versus untreated groups. ${ }^{*} P<0.05$ versus EGF-treated groups. Magnification: (c) 1:100.

Cell migration is a multistep process involving numerous soluble growth factors, cytokines and proteases as well as extracellular-matrix proteins and adhesion molecules [17,42]. Recent studies have implicated another important process, namely, water fluxes across the plasma membrane, which cause localized swelling of lamellipodia leading to cell migration [43,44]. During this process, termed osmophoresis, the vesicles/cells move towards hypo-osmolality as water enters the front end and leaves the rear end of the cell $[14,15]$. Furthermore, the notion that water fluxes have a great impact on cell migration primarily mediated by AQPs has been supported by a great deal of evidence $[14,15,45]$. At least 13 members have been identified to date in mammals [1,2]. However, AQP3 is the only one that has so far been found in the basal layer of keratinocytes in human skin system $[3,46]$. Hairless mice lacking AQP3 exhibit reduced stratum corneum hydration and delayed wound healing $[3,6,7]$. We for the first time present evidence that AQP3 is expressed in human skin fibroblasts and that EGF, which induces cell migration, also induces AQP3 expression in both skin fibroblasts and keratinocytes (Figures 2a-2e).

Is AQP3 involved in EGF-induced cell migration in human skin fibroblasts, knowingly important in wound healing? There are at present no selective AQP3 channel blockers for the study of AQP3 function; however, recently it has been demonstrated that copper $\left(\mathrm{CuSO}_{4}\right)$ or nickel $\left(\mathrm{NiCl}_{2}\right)$ inhibits both water and glycerol transport of AQP3 [30,31]. $\mathrm{CuSO}_{4}$ and $\mathrm{NiCl}_{2}$, applied in our experiments, remarkably reduced EGF-induced cell migration in a dose-dependent manner (Figures $3 \mathrm{a}$ and $3 \mathrm{~b}$ ). $\mathrm{CuSO}_{4}$, compared with the same dosage of $\mathrm{NiCl}_{2}$, exerted a more potent inhibitory effect on EGF-induced cell migration (Figures $3 \mathrm{c}$ and $3 \mathrm{~d}$ ). These results are consistent with previous studies that showed that $\mathrm{CuSO}_{4}$ has more a potent inhibitory effect than $\mathrm{NiCl}_{2}$ on AQP3 water permeability [30]. AQP3 expression, in cells treated with EGF together with $\mathrm{CuSO}_{4}$ or $\mathrm{NiCl}_{2}$, was comparable with cells treated with EGF alone. The cell morphology was also unchanged (Figures $4 \mathrm{c}$ and $4 \mathrm{~d}$ ). These results are also consistent with previous studies that have suggested that $\mathrm{CuSO}_{4}$ and $\mathrm{NiCl}_{2}$ do not necessarily enter cells to exert their inhibitory effect on AQP3, since the inhibitory effect is transient [30].
Existing results have shown that water and glycerol transport of AQP3 is also affected by mercury, another bivalent heavy metal, although the mechanism of action may be different from $\mathrm{NiCl}_{2}$ and $\mathrm{CuSO}_{4}$ [30-32]. In the present study, we investigated the effects of other bivalent heavy metals such as $\mathrm{MnSO}_{4}, \mathrm{CoSO}_{4}$, $\mathrm{MgSO}_{4}$ and $\mathrm{ZnCl}_{2}$ on cell migration. Interestingly, we found that $\mathrm{MnSO}_{4}$ and $\mathrm{CoSO}_{4}$, but neither $\mathrm{MgSO}_{4}$ nor $\mathrm{ZnCl}_{2}$, inhibited EGF-induced cell migration (Figures $4 \mathrm{a}$ and $4 \mathrm{~b}$ ). Collectively, it is highly likely that $\mathrm{NiCl}_{2}$ and $\mathrm{CuSO}_{4}$, both known as AQP3 water inhibitors, and other bivalent heavy metal such as $\mathrm{MnSO}_{4}$ and $\mathrm{CoSO}_{4}$, inhibit EGF-induced cell migration without affecting AQP3 expression and cell morphology.

Another question that remains unanswered is whether AQP3 is directly involved in cell migration. We found that AQP3 siRNA inhibited EGF-induced AQP3 protein expression and cell migration in human skin fibroblasts (Figures 5a and 5c), supporting the notion that AQP3 is directly involved in EGF-induced human skin fibroblast cell migration. It is likely that up-regulation of AQP3 induced by EGF, in addition to its water permeability to the leading edge, which can be inhibited by $\mathrm{CuSO}_{4}$ and $\mathrm{NiCl}_{2}$, may further augment the contribution of AQP3 to cell migration in human skin fibroblasts. Our results are consistent with recent findings that up-regulation AQPs are involved in many physiological and pathological functions, including cell migration. For example, AQP4 is up-regulated within the glial scar in response to brain injury in vivo $[15,47]$.

Our findings that EGF-induced AQP3 mediates human skin fibroblast cell migration are consistent with the recent discovery that AQP1 deletion reduces the migration speed of mouse aortic endothelial cells (in vitro and in vivo) and that transfection with functional AQP1 or AQP4 accelerates the migration of cultured Chinese-hamster ovary fibroblasts and Fisher rat thyroid epithelial cells [14]. AQP4 is also involved in astroglial cell migration, which occurs during glial scar formation [15]. Our results suggest that up-regulation of AQP3, another AQP besides AQP1 and $\mathrm{AQP} 4$, in response to EGF accelerates human skin fibroblast cell migration by increasing plasma-membrane water (with or without glycerol) permeability, which in turn increases the transmembrane water fluxes that take place during cell migration. 
Discovery of the AQP family of water channel proteins has provided insight into molecular mechanisms of membrane water permeability and cell migration. We found in the present study that EGF induces AQP3 expression, which is involved cell migration in human skin fibroblasts. However, the mechanisms through which EGF up-regulates AQP3 expression remain poorly understood. In the present study, we have provided the evidence that EGFR, ERK and PI3K mediate EGF-induced AQP3 expression and fibroblast migration. It has been well established that EGFR is an essential regulator of epidermal functions, including cell migration and wound healing $[23,48]$. In this study, we presented results demonstrating that both EGFR and its kinase activity are required for EGF-induced AQP3 expression and cell migration in human skin fibroblasts (Figures 6a, 6b, 6d, 6f and 6h).

Our study also showed that PI3K inhibitor LY294002 and MEK/ERK inhibitor U0126 inhibited cell migration induced by EGF in human skin fibroblasts and that PI3K/Akt inhibitor LY294002 and MEK/ERK inhibitor U0126 (Figures 7a and 7c), but not JNKi or p38 inhibitor SB203580 (results not shown) effectively inhibited EGF-induced AQP3 expression (Figure 7a) and cell migration (Figure 7c) in human skin fibroblasts. As expected, EGF transiently induced ERK1/2 and Akt phosphorylation (results not shown). These results clearly demonstrate that PI3K and ERK signalling pathways are involved in EGF-induced AQP3 expression and cell migration in human skin fibroblasts. We contend that ERK and PI3K are critical signal molecules selectively regulating AQP3 expression and/or function in human skin fibroblasts.

In conclusion, our findings demonstrate for the first time that AQP3 is expressed in human skin fibroblasts, in addition to human keratinocytes, and that EGF induces AQP3 expression and cell migration via EGFR, PI3K and ERK signal transduction pathway in human skin fibroblasts. Our findings also provide an explanation as to why AQP3 null mice display delayed recovery of wound healing compared with wild-type mice $[7,8]$. We propose a novel role for AQP3 in skin system: involvement in cell migration in human skin fibroblasts, which occurs during normal wound healing. It is envisioned that development of AQP3 openers or forced expression of AQP3 may be beneficial for human skin wound healing and may prevent human skin from dehydration.

This research was supported in part by a grant from the NIH [National Institutes of Health; P20 RR016457 from INBRE (IDeA Networks of Biomedical Research Excellence) Program of the National Center for Research Resources] and a grant for biomedical research from Rhode Island Foundation, and a grant from Slater Center for Environmental Biotechnology.

\section{REFERENCES}

1 King, L. S., Kozono, D. and Agre, P. (2004) From structure to disease: the evolving tale of aquaporin biology. Nat. Rev. Mol. Cell Biol. 5, 687-698

2 Verkman, A. S. (2005) More than just water channels: unexpected cellular roles of aquaporins. J. Cell Sci. 118, 3225-3232

3 Hara-Chikuma, M. and Verkman, A. S. (2005) Aquaporin-3 functions as a glycerol transporter in mammalian skin. Biol. Cell 97, 479-486

4 Ishibashi, K., Sasaki, S., Fushimi, K., Uchida, S., Kuwahara, M., Saito, H., Furukawa, T., Nakajima, K., Yamaguchi, Y., Gojobori, T. et al. (1994) Molecular cloning and expression of a member of the aquaporin family with permeability to glycerol and urea in addition to water expressed at the basolateral membrane of kidney collecting duct cells. Proc. Natl. Acad. Sci. U.S.A. 91, 6269-6273

5 Takata, K., Matsuzaki, T. and Tajika, Y. (2004) Aquaporins: water channel proteins of the cell membrane. Prog. Histochem. Cytochem. 39, 1-83

6 Ma, T., Hara, M., Sougrat, R., Verbavatz, J. M. and Verkman, A. S. (2002) Impaired stratum corneum hydration in mice lacking epidermal water channel aquaporin-3. J. Biol. Chem. 277, 17147-17153
7 Hara, M., Ma, T. and Verkman, A. S. (2002) Selectively reduced glycerol in skin of aquaporin-3-deficient mice may account for impaired skin hydration, elasticity, and barrier recovery. J. Biol. Chem. 277, 46616-46621

8 Hara, M. and Verkman, A. S. (2003) Glycerol replacement corrects defective skin hydration, elasticity, and barrier function in aquaporin-3-deficient mice. Proc. Natl. Acad. Sci. U.S.A. 100, 7360-7365

9 Martin, P. (1997) Wound healing - aiming for perfect skin regeneration. Science 276 , 75-81

10 Grinnell, F. (1994) Fibroblasts, myofibroblasts, and wound contraction. J. Cell Biol. 124 401-404

11 Gabbiani, G., Hirschel, B. J., Ryan, G. B., Statkov, P. R. and Majno, G. (1972) Granulation tissue as a contractile organ. A study of structure and function. J. Exp. Med. 135, 719-734

12 Condeelis, J. (1993) Life at the leading edge: the formation of cell protrusions. Annu. Rev. Cell Biol. 9, 411-444

13 Lauffenburger, D. A. and Horwitz, A. F. (1996) Cell migration: a physically integrated molecular process. Cell 84, 359-369

14 Saadoun, S., Papadopoulos, M. C., Hara-Chikuma, M. and Verkman, A. S. (2005) Impairment of angiogenesis and cell migration by targeted aquaporin-1 gene disruption. Nature 434, 786-792

15 Saadoun, S., Papadopoulos, M. C., Watanabe, H., Yan, D., Manley, G. T. and Verkman, A. S. (2005) Involvement of aquaporin-4 in astroglial cell migration and glial scar formation. J. Cell Sci. 118, 5691-5698

16 Chen, X. M., O'Hara, S. P., Huang, B. Q., Splinter, P. L., Nelson, J. B. and LaRusso, N. F. (2005) Localized glucose and water influx facilitates Cryptosporidium parvum cellular invasion by means of modulation of host-cell membrane protrusion. Proc. Natl. Acad. Sci. U.S.A. 102, 6338-6343

17 Ridley, A. J., Schwartz, M. A., Burridge, K., Firtel, R. A., Ginsberg, M. H., Borisy, G., Parsons, J. T. and Horwitz, A. R. (2003) Cell migration: integrating signals from front to back. Science 302, 1704-1709

18 Blay, J. and Brown, K. D. (1985) Epidermal growth factor promotes the chemotactic migration of cultured rat intestinal epithelial cells. J. Cell Physiol. 124, 107-112

19 Chen, J. D., Kim, J. P., Zhang, K., Sarret, Y., Wynn, K. C., Kramer, R. H. and Woodley, D. T. (1993) Epidermal growth factor (EGF) promotes human keratinocyte locomotion on collagen by increasing the alpha 2 integrin subunit. Exp. Cell Res. 209, 216-223

20 Fujii, K., Dousaka-Nakajima, N. and Imamura, S. (1995) Epidermal growth factor enhancement of HSC-1 human cutaneous squamous carcinoma cell adhesion and migration on type I collagen involves selective up-regulation of alpha 2 beta 1 integrin expression. Exp. Cell Res. 216, 261-272

21 Matthay, M. A., Thiery, J. P., Lafont, F., Stampfer, F. and Boyer, B. (1993) Transient effect of epidermal growth factor on the motility of an immortalized mammary epithelial cell line. J. Cell Sci. 106, 869-878

22 Basson, M. D., Modlin, I. M. and Madri, J. A. (1992) Human enterocyte (Caco-2) migration is modulated in vitro by extracellular matrix composition and epidermal growth factor. J. Clin. Invest. 90, 15-23

23 Carpenter, G. and Cohen, S. (1990) Epidermal growth factor. J. Biol. Chem. 265, 7709-7712

24 Brown, G. L., Nanney, L. B., Griffen, J., Cramer, A. B., Yancey, J. M., Curtsinger, III, L. J., Holtzin, L., Schultz, G. S., Jurkiewicz, M. J. and Lynch, J. B. (1989) Enhancement of wound healing by topical treatment with epidermal growth factor. N. Engl. J. Med. 321, 76-79

25 Samavati, L., Monick, M. M., Sanlioglu, S., Buettner, G. R., Oberley, L. W. and Hunninghake, G. W. (2002) Mitochondrial K(ATP) channel openers activate the ERK kinase by an oxidant-dependent mechanism. Am. J. Physiol. Cell Physiol. 283, C273-C281

26 Bandyopadhyay, B., Fan, J., Guan, S., Li, Y., Chen, M., Woodley, D. T. and Li, W. (2006) A 'traffic control' role for TGFbeta3: orchestrating dermal and epidermal cell motility during wound healing. J. Cell Biol. 172, 1093-1105

27 Fisher, G. J., Talwar, H. S., Lin, J., Lin, P., McPhillips, F., Wang, Z., Li, X., Wan, Y., Kang, S. and Voorhees, J. J. (1998) Retinoic acid inhibits induction of c-Jun protein by ultraviolet radiation that occurs subsequent to activation of mitogen-activated protein kinase pathways in human skin in vivo. J. Clin. Invest. 101, 1432-1440

28 Zhang, P., Chan, J., Dragoi, A. M., Gong, X., Ivanov, S., Li, Z. W., Chuang, T. H. Tuthill, C., Wan, Y., Karin, M. and Chu, W. M. (2005) Activation of IKK by thymosin alpha1 requires the TRAF6 signalling pathway. EMBO Rep. 6, 531-537

29 Yin, J. Q., Gao, J., Shao, R., Tian, W. N., Wang, J. and Wan, Y. (2003) siRNA agents inhibit oncogene expression and attenuate human tumor cell growth. J. Exp. Ther. Oncol. 3, 194-204

30 Zelenina, M., Tritto, S., Bondar, A. A., Zelenin, S. and Aperia, A. (2004) Copper inhibits the water and glycerol permeability of aquaporin-3. J. Biol. Chem. 279, 51939-51943

31 Zelenina, M., Bondar, A. A., Zelenin, S. and Aperia, A. (2003) Nickel and extracellular acidification inhibit the water permeability of human aquaporin-3 in lung epithelial cells. J. Biol. Chem. 278, 30037-30043 
32 Kuwahara, M., Gu, Y., Ishibashi, K., Marumo, F. and Sasaki, S. (1997) Mercury-sensitive residues and pore site in AQP3 water channel. Biochemistry 36, 13973-13978

33 Ullrich, A. and Schlessinger, J. (1990) Signal transduction by receptors with tyrosine kinase activity. Cell 61, 203-212

34 Chen, P., Xie, H., Sekar, M. C., Gupta, K. and Wells, A. (1994) Epidermal growth factor receptor-mediated cell motility: phospholipase $\mathrm{C}$ activity is required, but mitogenactivated protein kinase activity is not sufficient for induced cell movement. J. Cell. Biol. 127, 847-857

35 Shah, B. H., Neithardt, A., Chu, D. B., Shah, F. B. and Catt, K. J. (2006) Role of EGF receptor transactivation in phosphoinositide 3-kinase-dependent activation of MAP kinase by GPCRs. J. Cell Physiol. 206, 47-57

36 Shien, T., Doihara, H., Hara, H., Takahashi, H., Yoshitomi, S., Taira, N., Ishibe, Y., Teramoto, J., Aoe, M. and Shimizu, N. (2004) PLC and PI3K pathways are important in the inhibition of EGF-induced cell migration by gefitinib ('Iressa', ZD1839). Breast Cancer 11, $367-373$

37 Takata, K., Tajika, Y., Matsuzaki, T., Aoki, T., Suzuki, T., Abduxukur, A. and Hagiwara, H. (2004) Molecular mechanisms and drug development in aquaporin water channel diseases: water channel aquaporin-2 of kidney collecting duct cells. J. Pharmacol. Sci. 96, 255-259

38 Qiu, Q., Yang, M., Tsang, B. K. and Gruslin, A. (2004) Both mitogen-activated protein kinase and phosphatidylinositol 3-kinase signalling are required in epidermal growth factor-induced human trophoblast migration. Mol. Hum. Reprod. $\mathbf{1 0}$, $677-684$

Received 1 June 2006/6 July 2006; accepted 19 July 2006

Published as BJ Immediate Publication 19 July 2006, doi:10.1042/BJ20060816
39 Laato, M. and Niinikoski, J. (1990) Epidermal growth factor (EGF) and wound healing. Duodecim 106, 860-862

40 Schultz, G., Rotatori, D. S. and Clark, W. (1991) EGF and TGF-alpha in wound healing and repair. J. Cell Biochem. 45, 346-352

41 Uhl, D. (1991) PDGF, EGF and TGF-alpha. Promoters of cancer growth and wound healing. Med. Monatsschr. Pharm. 14, 130-131

42 Vicente-Manzanares, M., Webb, D. J. and Horwitz, A. R. (2005) Cell migration at a glance. J. Cell Sci. 118, 4917-4919

43 Condeelis, J., Bresnick, A., Demma, M., Dharmawardhane, S., Eddy, R., Hall, A. L., Sauterer, R. and Warren, V. (1990) Mechanisms of amoeboid chemotaxis: an evaluation of the cortical expansion model. Dev. Genet. 11, 333-340

44 Oster, G. F. and Perelson, A. S. (1987) The physics of cell motility. J. Cell Sci. 8 (Suppl.), $35-54$

45 Hara-Chikuma, M. and Verkman, A. S. (2006) Aquaporin-1 facilitates epithelial cell migration in kidney proximal tubule. J. Am. Soc. Nephrol. 17, 39-45

46 Sugiyama, Y., Ota, Y., Hara, M. and Inoue, S. (2001) Osmotic stress up-regulates aquaporin-3 gene expression in cultured human keratinocytes. Biochim. Biophys. Acta $1522,82-88$

47 Saadoun, S., Papadopoulos, M. C., Davies, D. C., Krishna, S. and Bell, B. A. (2002) Aquaporin-4 expression is increased in oedematous human brain tumours. J. Neurol. Neurosurg. Psychiatry 72, 262-265

48 Wells, A., Gupta, K., Chang, P., Swindle, S., Glading, A. and Shiraha, H. (1998) Epidermal growth factor receptor-mediated motility in fibroblasts. Microsc. Res. Tech. 43, 395-411 